\title{
FIFTEENTH ANNUAL MEETING
}

\author{
The Sociedad Latinoamericana de \\ Investigaciones Pediatricas
}

Cochabamba, Bolivia, December 1977

\section{The Psychomotor and Nutritional Development of Severe Marasmic Infants in Nutritional Recovery Centers}

MARTHA COLUMBO, JOSE M. CELEDON, JUAN KOVALSKY, AND CLAUDIO GREPPI Institute of Nutrition and Food Technology, Universidad de Chile, Santiago, Chile

Seventy infants with early and severe marasmic undernutrition were examined in a follow-up study after a treatment period in Nutrition Recovery Centers. Their psychomotor development was analyzed using an evaluation scale of psychomotor development standardized in Chile. The mean age of admission to the Nutritional Recovery Centers was $228 \pm 1-4$ days, and the length of hospitalization was $148 \pm 41$ days. On admission, the developmental quotient is $0.57 \pm 0.17$, indicating very severe psychomotor retardation of these infants. At discharge, this quotient is $0.77 \pm$ 0.15 , an increase that is statistically significant $(P<0.01)$. Analyzing the correlation between weight recovery and psychomotor development, there is an $r=0.18$ (N.S.) for infants under 6 months of age and $r=0.14$ (N.S.) for children over 6 months of age. Regarding nutritional recovery, on admission the average weight deficit was $-3.98 \mathrm{SD}$ (40\% weight deficit) which is reduced to $-1.93 \mathrm{SD}$ at departure (20\% weight deficit). This increase in weight is significant at $P<0.01$.

\section{Role of Normal Intelligence in Adequate School Adjustment \\ MARIA TERESA GUSMAN AND LUZ COUSINO Institute of Nutri- tion and Food Technology, Universidad de Chile, Santiago, Chile}

School adjustment was studied in a stratified random sample of third graders of public schools in Santiago, Chile $(n=562$ children). School adjustment was defined as satisfactory academic achievement and social relationships with classmates. The verbal scale of the WISC was used (standardized in Santiago) to measure intellectual capacity. Three groups resulted: below normal (61-90), normal (91-110), and above normal (111 and higher). Academic achievement was evaluated in verbal and mathematic abilities. Special tests were constructed and standardized for this objective. The results were scored and divided into quartiles for interpretation. The social relationships were studied by the Johnston sociometric technique ("Guess who is the child that. .."). There was no significant relationship between sex and academic achievement. There was a significant relationship between academic achievement and mathematic ability $(P<0.001)$, verbal $(P<$ $0.001)$, and general achievement $(P<0.001)$. The normal $1 Q$ group had a normal distribution in the four achievement groups. The below normal and the above normal children fell into the lowest and highest achievement groups. In the area of social relationships, it was observed that the above average group had more leadership or acceptance by their classmates. Good achievement is highly correlated with leadership and peer acceptance. In the normal IQ group, more than $60.2 \%$ of the children are not seen as leaders and $61.5 \%$ are not accepted by their classmates. Fifty percent of the normal IQ group were rejected by peers or their classmates. The results show that intelligence is an important variable in the school adjustment. It could be seen as a necessary condition inasmuch as a high percentage of the low intellect group usually fail in school and a high percentage of the high intellect group succeed in school. The normal intellect group varies in its adjustment, depending upon other factors that are now being studied.

\section{Intestinal Absorption of Electrolytes in Marasmic Children with Diarrheal Dehydration}

A. L. GARDOSA, G. SPEROTTO, AND F. R. CARRAZZA Clinical Research Center of the Children's Instituto, Hospital das Clinicas, Sao Paulo, Brazil

A study was performed to estimate intestinal absorption of electrolytes, administered in cow's milk, during recovery from diarrheal dehydration. Seven marasmic children with diarrheal dehydration and estimated acute losses of over $10 \%$ of body weight were studied. Metabolic balance collections were performed for at least 6 days, starting from admission. After recovery from the acute episode all children had weight and height under the third percentile for Brazilian standards and were free of edema.

Recovery was uneventful for all children, with improvement of diarrhea on the third day. During the first day, no milk was administered, one-third strength cow's milk was started on the second day and, depending on tolerance, increased in amount and strength to whole cow's milk by the end of the sixth day.

Significant correlations between amounts ingested and absorbed were observed for all electrolytes from the fourth day onwards. The average percentage of absorption of $\mathrm{Na}, \mathrm{K}$, and $\mathrm{Cl}$ increased from the third day onwards, with significant differences of the second day in relation to the fifth and sixth days. The average percentage of absorption of $\mathrm{Ca}, \mathrm{Mg}$, and $\mathrm{P}$ was almost constant from the second day.

This study shows that in marasmic children with diarrheal dehydration absorption of electrolytes in cow's milk can be predictable only when diarrhea improves. During the initial recovery period, no correlation was found between amounts administered and absorbed. 